\title{
VIVENCIANDO A VISITA DOMICILIAR APESAR DE TUDO ${ }^{1}$
}

\author{
LIVING A DOMICILE VISIT IN SPITE OF ALL \\ VIVENCIANDO LA VISITA DOMICILIAR APESAR DE TODO
}

Elaine Cristina Tulio*

Maguida Costa Stefanelli**

Maria de Lourdes Centa***

\begin{abstract}
RESUMO: Para conhecer o mundo da família, o local onde ela vivencia seu dia-dia, a visita domiciliar, quanto realizada adequadamente, é uma das ações que pode facilitar sua compreensão e seu cuidado. 0 Programa de Saúde da Família, do Ministério de Saúde, tem entre suas ações a visita domiciliar, da qual participam os elementos da equipe de saúde. Considerando que nem sempre há tempo para o preparo adequado da equipe para implementação de um plano de ação, temos como objetivo descrever como é vivenciada a visita domiciliar pelos membros da equipe multiprofissional de uma Unidade de Saúde da cidade de Curitiba. R ealizou-se uma pesquisa tipo etnográfica. $\mathrm{O}$ instrumento de coleta de dados utilizado foi a entrevista com observação. $\mathrm{Na}$ análise dos dados foi possível identificar as seguintes categorias: "realizando a visita", "sentindo-se aceitos", "relatando os tópicos abordados", "vinculando fatores sócio-econômicos e políticos", "valorizando a família", "dando sugestões". Articulando as categorias e reanalisando-as, chegamos ao tema central: "Vivenciando a visita domiciliar a pesar de tudo". Os resultados evidenciaram que a equipe possui um papel de vital importância junto à família, sobre a conduta a ser tomada em cada situação. Constatamos ainda que a equipe dá as orientações necessárias, mas associam a estas alguns problemas sócio-econômicos e políticos que estariam prejudicando o processo vivenciado.
\end{abstract}

PALAVRAS CHAVE: Saúde da família; Família; Visitantes domiciliares; Equipe de assistência ao paciente.

\section{INTRODUÇÃO}

Ter a família como centro de atenção na área de saúde é uma dimensão que merece ser destacada, tanto para a prática do cuidado à saúde como para a construção do conhecimento nesta área. Isto pode ser verificado através da política de Saúde do Ministério de Saúde (MS) por meio do Programa de Saúde da Família - PSF ( Brasil, 1994).

Considerando a extensão do nosso País, as diversidades regionais, políticas, socioeconômicas e culturais, além da diversificação da qualificação profissional, nota-se que nem sempre é possível aos técnicos que elaboram os planos governamentais de saúde, observarem o quantitativo e qualitativo das ações de saúde existentes nas unidades ou das que irão colocá-los em prática dentro das realidades vividas pelos profissionais que atuam nas unidades básicas de saúde ou seja na porta de entrada do sistema de saúde. 0 preparo em geral, é realizado em caráter emergencial, tornando-se um programa à mais, a ser executado pela equipe pré-existente, o que geralmente faz com que essa equipe enfrente problemas na implantação e implementação das atividades que compõem os programas determinados.

Para implementar um programa de saúde dirigido à família torna necessário conhecer seu modo de vida, a comunidade em que vive, sua cultura, crenças e padrões de comportamento. Para que isso ocorra, é de grande importância conhecer o território onde a família está inserida, seu modo de vida, podendo isso ser

\footnotetext{
Projeto do Grupo de Estudo Família, Saúde e Desenvolvimento. Apresentado ao EVINCI, sendo premiado em terceiro lugar pela banca de avaliação dos trabalhos.

* Bolsista ICICNPq. Departamento de Enfermagem da Universidade Federal do Paraná (UFPR). Membro do Grupo de Estudo Família, Saúde e Desenvolvimento (GEFASED).

** Enfermeira. Doutora em Enfermagem. Professor Titular Visitante do Departamento de Enfermagem UFPR. Membro do GEFASED.

*** Enfermeira. Doutora em Enfermagem. Professor Adjunto IV do Departamento da UFPR. Coordenador do GEFASED.
} 
facilitado por meio da visita domiciliar (VD), que pode ser considerada como um dos instrumentos de compreensão do viver em família.

O PSF, do MS, tem entre suas ações a VD, da qual devem participar os elementos da equipe de saúde como, médicos, odontólogos, enfermeiros, auxiliares de enfermagem e os agentes comunitários.

Vários estudos encontrados nas bases de dados Lilacs e Medline, apontam e direcionam seus resultados, para o conceito e custos da VD, como pode-se observar nos trabalhos de Groon et al. (2000), Byrd (1995) entre outros.

A importância da VD como alternativa assistencial é destacada por Padilha et al. (1994), no atendimento à pacientes com problemas específicos, no ambiente familiar. Este autor considera a VD meio para adequar conhecimentos e procedimentos adquiridos pelos profissionais às condições sociais, econômicas, ambientais e culturais do cliente-família. A VD faz parte, também, do panorama da área de pesquisa, quando busca-se obter dados para identificar problemas que atingem indivíduos e suas famílias em situações específicas, como apontam Polak et al. (1998), Glasham e Diccini (1997), Azevedo et al. (1989), Santos (1997) entre outros. Dentre estas situações podemos destacar como condições especiais a dos indivíduos que realizam diálise peritonial, os portadores de asma, queimados, idosos, entre outros problemas vigentes na área de abrangência do local de atendimento de cada unidade de saúde.

Temos como exemplo das atividades da VD o trabalho de Abrantes (1996), que desempenha atividades junto a crianças e adolescentes em um abrigo denominado Casa-lar, com o objetivo de fortalecer os projetos de vida dos que lá residem. Estes projetos são discutidos levando-se em consideração os fatores educacionais, afetivos e de realização pessoal da clientela alvo. $\mathrm{Na}$ Casa-lar, realizam-se oficinas de sensibilização e entrevistas relativas as condições de vida do próprio residente e sua família, destacando-se os aspectos de perda de identidade e sentido da vida.

Nos PSF a VD é tida como ação de saúde capaz de melhorar as condições de vida e de saúde das famílias de determinado território.

A visita domiciliar é a ação que permite ao profissional de saúde, estar mais próximo do cotidiano das famílias permitindo-Ihes conhecer, interpretar e vivenciar o meio onde elas vivem, identificando assim, os vários problemas que afetam a sua realização. Dado nosso interesse em buscar respostas para questionamentos sobre VD decidimos realizar este estudo junto a equipe multiprofissional de saúde que a realiza. Dentre os nossos questionamentos, temos: o que pensam os profissionais da equipe de saúde sobre a VD? Como sentemse ao realizarem a VD? Como são recebidos pelas famílias? Como percebem a participação das famílias?

\section{REVISÃO DE LITERATURA}

O PSF (Brasil,1994) foi concebido com o objetivo de proceder "a reorganização da prática assistencial em novas bases e critérios, em substituição ao modelo tradicional de assistência". Foi criado com o intuito de reestruturar o modelo de atenção à saúde o qual deve estar centrado na família, entendida e percebida a partir do seu ambiente físico e social, o que vem possibilitando às equipes uma compreensão ampliada do processo saúde-doença e da necessidade de intervenções que vão além de práticas curativas. Este programa está centrado na vigilância à saúde, trabalha com famílias inseridas em território de abrangência definido e com equipe de saúde multiprofissional.

Uma equipe de saúde da família tem como objetivo buscar a promoção da saúde, tendo como compromisso, o incentivo à uma vida plena e a responsabilidade com seu meio ambiente. 0 profissional interage com a família em seu processo de viver, ser saudável/adoecer havendo interação, ou seja, uma troca de saberes, onde ambas, a família e a equipe podem sair enriquecidas.

O PSF, de acordo com o MS, prioriza as ações de proteção e promoção à saúde dos indivíduos e da família de forma integral e contínua, adotando um novo paradigma: a qualidade de vida.

O PSF está voltado para o benefício de toda a população, respondendo às suas necessidades, desde seus problemas mais simples até suas questões mais complexas, levando em conta o meio em que vive e indo além da concepção biológica, contextualizando o indivíduo em sua realidade familiar e social. BOMAR (1990), em seu conceito de saúde da família deixa clara a concepção: “é maior do que a ausência de doença de um 
membro da família, ela inclui uma multiplicidade de variações biológicas, psicológicas, sociológicas, espirituais, dentro de um contexto cultural que a família vivencia enquanto sente bem-estar ou doença".

O PSF proporciona a desburocratização do atendimento, através da atenção integral e contínua a todos os membros da família. A equipe básica, deve ser composta, no mínimo, por médico, odontólogo, enfermeiro, auxiliar de enfermagem e quatro a seis agentes comunitários, sendo que estes números podem ser alterados de acordo com a realidade e disponibilidade local.

O objetivo geral do PSF é melhorar o estado de saúde da população, mediante a construção de um modelo assistencial de atenção baseado na promoção, proteção, diagnóstico precoce, tratamento e recuperação da saúde, em conformidade com os princípios e diretrizes do Sistema Único de Saúde (SUS) e dirigido aos indivíduos, à família e à comunidade. Uma das atividades da equipe do PSF é o atendimento à comunidade, tendo como uma de suas atividades a VD (Brasil, 1994).

Além do atendimento a consultas na Unidade de Saúde, os profissionais de saúde, percorrem os bairros, visitando as casas, dentro de sua área de abrangência, pois, a VD permite aproximar a equipe de saúde da comunidade, propiciando-lhe um acompanhamento mais particularizado das famílias. Os profissionais passam, então, a conhecer não só o quadro clínico e problemas de saúde mas, também, as sua condições de vida, em termos econômicos, culturais, sociais e familiares. A visita domiciliar é fator essencial ao processo de vigilância à saúde e interação entre a equipe e comunidade, tendo por finalidade acompanhar a situação de saúde das famílias, esperando-se, assim, resultados positivos através da antecipação do diagnóstico personalizado do atendimento e de uma maior orientação ao indivíduo e sua família.

Segundo Nogueira (1997), a VD é um método de trabalho de enfermagem junto ás famílias, tendo como vantagens: proporcionar, ao indivíduo, o conhecimento no seu próprio meio ambiente, atentando-se para as condições de habitação, relações afetivas, sociais da família; facilitar a adaptação e planejamento da família conforme seus próprios recursos; proporcionar melhor relacionamento do profissional com a família, pois ela é menos formal do que as atividades desenvolvidas nos serviços de saúde; proporcionar maior liberdade para que os clientes explorem seus problemas, pois o tempo dedicado a eles é bem maior do que no contexto institucional, além de outros.

A VD permite ao profissional criar um relacionamento afetivo e amistoso com a comunidade envolvida, pois ele está adentrando em seu lar, sua casa, sua intimidade, mantendo assim interações, ou seja, relacionamento interpessoal, que permite obter dados mais fidedignos sobre a saúde das famílias. Para isso é necessário estabelecer confiança entre os membros da equipe de saúde e os da família, para que esta sinta-se segura com as ações desenvolvidas pelos profissionais e em casos de problemas ou dúvidas, solicite ajuda, explicações e orientações. Ela serve, também, para que os profissionais entendam o significado do momento vivido e possam atender as necessidades evidenciadas e as solicitações feitas, ajudando a família a descobrir suas possibilidades. Quanto mais efetivo for o relacionamento e o envolvimento do profissional com a família, maior será o seu reconhecimento como profissional.

Para proporcionar assistência à saúde com qualidade, é necessário entender cada família como única, pertencente a um contexto social e cultural específico que condiciona diferentes formas de viver e adoecer. Para atender as necessidades vividas pelas famílias, os profissionais de saúde utilizam-se da VD como instrumento de interação, resolutividade, procurando assistir/cuidar de forma adequada à proporcionar-lhes meios para terem uma vida mais saudável.

\section{OBJ ETIVO}

O objetivo deste trabalho, portanto, é descrever como é vivenciada a VD pelos membros da equipe multidisciplinar, que atuam no PSF, em uma Unidade de Saúde, de um bairro da cidade de Curitiba.

\section{REFERENCIAL METODOLÓGICO}

Optou-se pelo método qualitativo porque ele permite compreender os diversos aspectos vivenciados pelos profissionais que realizam a VD e a prender o significado que esta ação tem para eles. Para R ubin (1995), a entrevista qualitativa, permite entender a experiência do respondente, mesmo que se depare com várias 
versões sobre determinados acontecimentos, pois estas refletirão as diferentes perspectivas do que está ocorrendo. Para Minayo (1994), este método favorece o aprofundamento do significado das crenças e dos valores dos indivíduos, permitindo o conhecimento do significado das ações e das relações humanas.

Trata-se de um estudo descritivo tipo etnográfico. A etnografia é um método de pesquisa que viabiliza o estudo de crenças, valores, padrões de comportamento de um grupo cultural ou de uma cultura, propiciando a inclusão dos aspectos culturais no atendimento e cuidado prestados pelos profissionais de saúde, àqueles que requerem o seu conhecimento e atuação. Permite aprender o significado do que as pessoas atribuem aos acontecimentos da vida e compreender suas crenças, valores e atitudes.

Adotando como cultura, o conceito de Leininger (1991), podemos perceber a importância de estudos, a este respeito, para a área de saúde. Para esta autora, cultura é o conjunto aprendido, partilhado e transmitido de crenças, valores, padrões de comportamentos e práticas de um grupo cultural, que orientam pensamentos, decisões e ações das pessoas que o compõem. 0 estudo etnográfico tem como objetivo a compreensão do fenômeno saúde-doença sob a perspectiva daqueles que o vivenciam, nos diversificados cenários culturais.

Etnografia para Leininger (1985), é um processo sistematizado de observar, detalhar, descrever, documentar e analisar o estilo de vida ou padrões específicos de uma cultura, com a finalidade de aprender 0 seu modo de viver, no seu ambiente natural. É um método eficaz, para obtenção de dados sobre fatos, sentimentos, visão de mundo, os quais permitem a compreensão das pessoas, em relação à símbolos, rituais e padrões culturais, exteriorizados.

\section{ASPECTOS ÉTICOS}

Neste trabalho seguiu-se o preconizado pela Resolução № 196/96 (Brasil, 1996) sobre pesquisa envolvendo seres humanos. Os informantes deram consentimento para a efetivação da pesquisa e tiveram a liberdade de expressar suas opiniões e sentimentos, cabendo ao entrevistador a posição de estimulá-los, para o fornecimento de dados necessários à realização do estudo.

\section{CENÁRIO DO ESTUDO}

O estudo foi desenvolvido em uma Unidade de Saúde, da cidade de Curitiba, que abrange aproximadamente 9858 habitantes. Na Unidade há 34 funcionários e destes, 4 são médicos, 3 enfermeiros, 3 dentistas, 14 auxiliares de enfermagem, 2 assistentes de serviços gerais, 1 técnico do serviço de administração, 2 técnicos de higiene dental (THD), 5 assistentes de cirurgião dentista (ACD), sem contar os 15 agentes comunitários. A Unidade oferece, a população local os seguintes programas: Programa da Gestante, Lactente, Hipertenso, Diabético, Planejamento Familiar entre outros, assim como o PSF, o qual foi implantado no segundo semestre de 1996, sendo unidade piloto.

\section{APRESENTAÇÃO DOS INFORMANTES}

O número dos informantes totalizou 13 profissionais da equipe multiprofissional da Unidade de Saúde. Houve saturação dos dados na 13a entrevista.

A seguir, na Tabela 1, apresentamos a caracterização dos informantes.

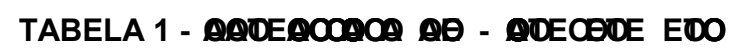

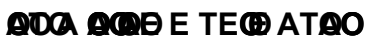

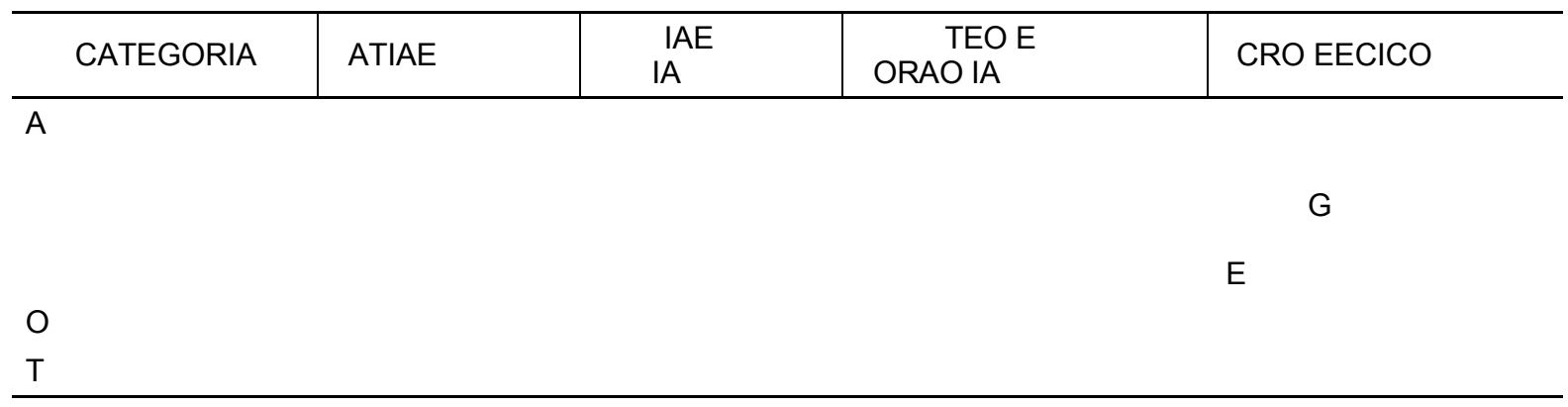


A idade média dos informantes é 41 anos. E m relação ao tempo de formação, observamos que a maioria encontra-se em média com 10 anos de profissão. Apenas 1 dos entrevistados tem curso de especialização em PSF. Não foi possível entrevistar o profissional enfermeiro.

\section{OBTENÇÃO DOS DADOS}

Os dados foram obtidos por meio de entrevista semi-estruturada e observação da atuação dos profissionais da Unidade de Saúde, quando da realização da VD, uma vez que este é o foco de estudo.

\section{APRESENTAÇÃO E ANÁLISE DOS DADOS}

A pós a obtenção, organização dos dados, seguindo sua convergência e divergência, foi possível identificar as seguintes categorias ou descritores culturais:

- realizando a visita;

- sentindo-se aceitos;

- relatando os tópicos abordados;

- vinculando fatores sócio-econômicos e políticos;

- valorizando a família;

- dando sugestões.

Articulando as categorias e reanalisando-as, chegamos ao tema cultural "VIVENCIANDO A VISITA DOMICILIAR APESAR DE TUDO", foi identificado como tal, por estar presente nos discursos e no dia-a-dia dos informantes.

\section{REALIZANDO A VISITA}

Há queixas de falta de funcionários, dificultando a realização das visitas, tempo para fazerem as visitas que julgam necessárias, existência de cães e violência que, às vezes, impede os profissionais de entrarem na rua, em que irão realizar a visita e, ainda, a limitação de dias para sua realização, não conseguindo assim, chegar ao objetivo desejado. Alguns disseram que "como está organizado está bom". Apesar das queixas fazem e valorizam a visita. Como pode-se observar:

"Há pouco funcionário, material e apoio para realizar as visitas".

“... o número de visitas, pelo menos todo dia e não uma vez por semana".

"o único problema são os cachorros e a violência nas ruas, isso é que dá medo".

"Há muitos programas na unidade de saúde, se sair alguém fura o programa...".

\section{SENTINDO-SE ACEITOS}

Aceitação é uma necessidade básica do ser humano. Todos nós precisamos nos sentir aceitos para experimentar satisfação e segurança nas experiências vividas. Alguns elementos da equipe que realizam a visita domiciliar verbalizaram o "sentirem-se aceitos" de maneira enfática.

Na visita, após ser criado um vínculo, os profissionais são aceitos de forma amistosa e até são convidados a entrarem nas residências e participarem das refeições e do chimarrão, entre outros.

"Aceitam muito bem. Somos convidados para entrar na casa. É como se estivessem esperando a gente chegar".

"Ficam super felizes, ficam esperando com a casa arrumada e nos convidam para entrar".

“... eles adoram, querem que a gente tome chimarrão com eles".

"Aceitação ótima... percebemos boa aceitação mostrando interesse". 
Alguns profissionais informaram que há interesse, porém introduzem alguns elementos res tritivos na sua fala.

"Boa aceitação, geralmente peço que a pessoa se aproxime para começar a falar, mesmo que ela insista em atender-me da janela".

"Depende da família e do profissional que está indo. Se esses são bem atendidos na unidade de saúde somos bem atendidos e aceitos na casa deles. Caso contrário, abrem e fecham a janela na nossa cara".

“... tem pessoas que nos tratam muito bem... e tem outras que nos recebem dizendo, o que vocês querem, do que se trata".

“... nos convidam para entrar... quando não, é uma família que bate a porta e nos joga pedras".

\section{RELATANDO OS TÓPICOS ABORDADOS}

Ao relatar os tópicos abordados durante a VD, os profissionais informaram que os familiares aproveitam para tirar suas dúvidas e questionam sobre a doença, remédios, estado de saúde, sendo alguns só se interessam por este último tópico.

"Através de perguntas...demonstrando interesse relativo à problemas de saúde".

“E les perguntam muito sobre tudo, sobre a doença, o remédio, o que fazer..., às vezes até perturbam demais".

Alguns referiram-se ao modo como as famílias participam da evolução das visitas de acordo com a etapa do curso da vida que estão vivendo.

"Pedem orientações, fazem perguntas, não só sobre a doença ou problema; mas sobre questões do dia-a-dia".

"Perguntam pouco no começo, depois participam melhor, com perguntas, o retorno é depois".

"As pessoas mais adultas participam ativamente. Os adolescentes geralmente se escondem ou riem debochadamente".

Alguns informantes revelaram que as famílias abordam o atendimento do posto, criticando quanto à falta de remédio e reclamando do atendimento médico.

"Ah! eles ouvem e reclamam da vida, do posto, da falta de remédio... quase não pedem orientações.

Reclamam dos médicos e do atendimento, eu acho que eles aproveitam para desabafar".

\section{VINCULANDO FATORES SÓCIO-ECONÔMICOS E POLITICOS}

Existem muitas situações difíceis que ocorrem na VD. São fatores que estão presentes no dia-a-dia da sociedade onde vivemos e que prejudicam a realização e execução da mesma. Os fatores sociais, econômicos e políticos ficam evidenciados nas falas dos profissionais e refletem os problemas existentes para a implementação e desenvolvimento do PSF nessa Unidade.

"Há poucos funcionários, material e apoio para realizar as visitas...".

"O número de funcionários é insuficiente."

“Há muito fluxo de pessoas dentro da unidade de saúde e não dá para sair e fazer as visitas".

"O único problema são os cachorros.... isso é que dá medo". 


\section{VALORIZANDO A FAMÍLIA}

Há uma forte interação entre equipe e família. Isto é percebido e interpretado pelo modo como a família é tratada, reconhecida e valorizada pela equipe de saúde. Esta valoriza as famílias, estabelecendo o clima amistoso e agradável, facilitando, assim, a atuação profissional.

"Percebemos boa aceitação e interesse da família."

"Eles nos aceitam como se fossemos da família".

"Cada um tem sua área, isso auxilia bastante, por causa do vínculo que criamos com a família".

"Elas recebem bem, elas sabem o que é bom para elas"

\section{DANDO SUGESTÕES}

As sugestões giraram em torno da escassez de funcionários, do excesso de programas existentes na Unidade, dos dias destinados à VD, da falta de equipe completa e dos problemas enfrentados, pela área de saúde, no nosso dia-a-dia.

"Aumentar o número de dias na semana para realizar as visitas".

"Se tivéssemos mais funcionários e tempo, seria bem melhor".

"Ter mais tempo".

"Ter mais autonomia e mais condições técnicas para resolução de problemas".

“Ter afinidade com a família”.

"Ter pessoas treinadas em PSF e que sejam craques".

Por outro lado, alguns deram sugestões relacionadas à mais famílias em si.

"Aceitar e respeitar a família, qualquer que seja o grau e em que ela se encontre".

\section{TEMA CULTURAL}

A partir da análise das falas dos informantes, profissionais da equipe de saúde, que realizam a VD e da nossa imersão nos dados brutos e reflexão sobre os descritores construídos, chegamos ao tema cultural deste estudo, que é:

\section{VIVENCIANDO A VISITA DOMICILIAR, APESAR DE TUDO}

Para que se possa realizar e atingir os objetivos da VD, é necessário respeitar e considerar as diferentes realidades, crenças, experiências, vivências e culturas das famílias. Os profissionais, ao por adentrar a casa e a privacidade das famílias, precisam saber interagir com as mesmas, considerando suas histórias de vida, seus sentimentos e emoções.

Respeitar crenças e cultura das famílias é fundamental ao profissional que realiza a VD, para que haja um entendimento eficaz sobre a questão saúde-doença.

Em cada família encontramos crenças, valores, conhecimento e experiências historicamente adquiridos e acumulados através das gerações. De acordo com seu modo de vida, a família organiza-se, adapta-se e constrói sua identidade, pois segungo Ullmann (1991), "Na sua vivência, o homem adapta o mundo a sua existência, transforma o que lhe é dado pela natureza, confere-lhe sentido, cria a cultura, condicionando sua forma de viver em sociedade". 
Para Nogueira (1977), no ambiente familiar, quer sob aspectos físicos quer de relacionamento afetivosocial, é que se constrói o conjunto das mais poderosas forças que influenciam a promoção, proteção e recuperação da saúde dos indivíduos.

É importante que a VD seja entendida e percebida como uma continuidade da atenção à saúde das pessoas, pois atende as famílias de maneira individualizada, respeitando a sua diversidade cultural. Ela propicia ao profissional, participar da vida das famílias, entrando no seu meio e vivenciando o seu dia-a-dia, o que the confere certa autonomia segundo os valores, crenças e padrões de comportamento familiar.

Os informantes que realizam a VD, sentem-se aceitos pelas famílias apesar de suas queixas. Nem sempre a aceitação e participação das famílias são expressas de imediato, mas surgem progressivamente, motivando os profissionais para a realizarem apesar dos obstáculos.

$\mathrm{Na}$ realização destas visitas conhece-se mais de perto as famílias. Nelas os profissionais tornam-se conhecedores das facilidades e dificuldades vivenciadas pelas mesmas, de forma particular, o que lhes permite uma atuação mais eficiente, a qual é valorizada e reconhecida tanto pela família como pela equipe e comunidade.

Os informantes queixam-se da situação existente para a realização da VD, apontam fatores sociais, culturais, econômicos e políticos que interferem na sua atuação, criticam, oferecem sugestões, mas apesar de tudo, realizam a VD reconhecendo o seu valor.

Assim, os membros da equipe de saúde que participam do PSF e realizam a VD, experimentam o próprio atendimento de suas necessidades de segurança e satisfação ao procurar atender as necessidades experimentadas pela família e seguem "VIVENCIANDO A VISITA DOMICILIAR APESAR DE TUDO".

\section{CONSIDERAÇÕES FINAIS}

Os resultados evidenciaram que o pessoal da equipe multiprofissional, possui um papel de vital importância, e o consideram como tal, pois são eles quem, na maioria das vezes, presenciam e avaliam o estado de saúde no domicílio, favorecendo o desenvolvimento e fortalecimento de relações mais afetivas com a família.

Constatamos ainda, que os integrantes da equipe de saúde, dão as orientações necessárias, mas associam a estas alguns problemas sócio-econômicos e políticos que estariam prejudicando o processo vivenciado. Através da descrição dos próprios informantes, sobre sua experiência e através da observação, pudemos notar a vontade que eles têm de realizar as VD, apesar de todos os problemas.

Tornou-se evidente que a VD é importante, principalmente, quanto ao aspecto educativo, pois o profissional de saúde tem a possibilidade de, no ambiente familiar, esclarecer seus membros e orientá-los sobre seus problemas de saúde, considerando os aspectos preventivos, curativos e de reabilitação.

A VD proporciona uma visão mais ampla das reais condições de vida da família e possibilita uma interação em ambiente tanto familiar, quanto social, através do conhecimento de seu cotidiano, de sua cultura, seus costumes, suas crenças, o que torna essas vivências enriquecedoras para ambos.

Com o exposto acima, concluimos que quando há vontade política para mudar, tudo se torna mais fácil, e nos dá a oportunidade de sonhar com um amanhã diferente para a saúde do povo brasileiro.

ABSTRACT: Aiming to know the world of the family, the place where it lives, its doily life, the domicile visit adequately done, is one of the actions which can facilitate its comprehension and care. The Family Health Program of the Health Ministry has among its actions the domicile visit, where the elements of the health team participate. Considering that time is not always enough to the adequate preparation of the team to implement a plan of action, we have as purpose to describe how the domicile visit is lived by the members of the multiprofessional team of health unit of the city $C$ uritiba. It was am ethnographic research. The interview with observation was used as instrument of date collection.On the analysis of date it was possible to identify the following categories: "doing the visit", "feeling accepted", "narrating the approached topics", "linking socio economic and politic factors", "valorizing the family", "giving suggestions". Articulating and analyzing the categories we got to the central theme: "Living the domicile visit in spite of all". The results show that the team has a part of main importance close to the family, over the conduct taken each moment. We also verified that the team give the necessary orientations, but associate some socio economic and politic problems, which could prejudice the process. 
KEY WORDS: Health education; Family; Home health aides; Patiant care team.

RESUMEN: Para conocer el mundo de la familia, el lugar donde ella vivencia su día-día, la visita domiciliar, cuando realizada apropiadamente, es una de las acciones que pueden proveer su comprensión y su cuidado. EI Programa de Salud de la Familia, del Ministerio de la Salud, tiene entre sus acciones la visita domiciliar, del qué participan los elementos del equipo de salud. Considerando que ni siempre hay tiempo hacia el preparo adecuado del equipo para la implantación de un plan de acción, nosotros tenemos como objetivo describir como es vivenciada la visita domiciliar para los miembros del equipo de una Unidad de Salud de la ciudad de Curitiba. Hubo hecho una investigación etnográfica. El instrumento usado para la colecta de datos fue la entrevista con observación participante. En el análisis de los datos hubo posible identificar las categorías siguientes: “ logrando la visita", aceptándose"," diciendo los temas acercados" ," vinculando los factores socio-económico y político"," valorando a la familia"," dando sugerencias". Articulándo las categorías , nosotros llegamos al tema central: "Vivenciando la visita domiciliar a pesar de todo". Los resultados evidenciaron que el equipo posee un papel de importancia vital acerca de la familia, en la conducta para ser tomada en cada situación. Nosotros verificamos aunque el equipo provee orientaciones necesarias, pero ellos asocian a éstos algunos problemas socio-económicos y políticos que estarían dañando la vivencia del proceso.

PALABRAS CLAVE: E ducacion en salud; Familia; Auxiliares de salud a domicilio; Grupo de atencion al paciente.

\section{REFERENCIAS BIBLIOGRÁFICAS}

1. AZEVEDO, D. et al. Assistência de enfermagem ao cliente queimado no ambulatório e/ou no domicilio após alta da unidade de internação. Rev. Bras. Enfermagem, São Paulo, v.42, n.1/4, p.60-67, 1989.

2. BRASIL. Ministério da Saúde. Secretaria de Assistência à Saúde. Coordenação de Atenção Básica. Avaliação da implantação e funcionamento do Programa de Saúde da Família (PSF). Brasília, 1994.

3. BRASIL. Ministério da Saúde. Conselho Nacional de Saúde. Resolução 196/96. Brasília. 1996.

4. BYRD, M.E. The home visiting processin the contexts of the voluntary vs. Required visit: examples from fieldwork. Public Health Nurs., Boston, v.12, n.3, p.196-202, 1995.

5. GLASHAN, R.Q.; DICCINI, S. Assistência de enfermagem domiciliar à criança asmática. Acta Paul. Enfermagem, São Paulo, v.10, n.2, p.62-68, 1997.

6. GROOM L. et al. The impact of nursing home patients on general practitioner's workloard. Br. J . Pract., v.50, p.473-476, 2000.

7. LEININGER, M.M. Qualitative research methods in nursing. Detroit : Grune\&S tratton, 1985. p. 33-71.

8. MINAYO, M.C. de S. et al. Pesquisa social: teoria, método e criatividade. 3 ed. Petrópolis : Vozes, 1994.

9. NOGUEIRA, M.J. FONSECA,R.M.G.S. A visita domiciliar como método de assistência de enfermagem da família. Rev. Esc. Enfermagem USP, São Paulo, v.11, n.1, p. 28-50, 1997.

10. PADILHA, M.C.S. et al. Visita domiciliar: uma alternativa assistencial. Enfermagem UERJ , v.2,n.1,p.83-90, 1994.

11. POLAK, Y.N. SOUZA; M, M.F.; CANALI, J .F. Cuidado domiciliar e o processo de redefinição da identidade do adulto em CAPD. Cogitare Enferm, Curitiba, v.3, n.1, p. 61-65, 1998.

12. RUBIN, H.J .; BUBIN,I.S. Qualitative interviewing: the art of hearing data. Thousand Oask : Sage,1195.

13. STORT, E.V.R. Cultura, imaginação e conhecimento: A educação e a familiarização da experiência. Campinas: UNICAMP,1993.

14. ULLMANN, R. A. Antropologia: o homem e a cultura. Petrópolis : Vozes, 1991. 